\title{
Inhibition Effect of Phosphorus Flame Retardants on the Fire Disasters Induced by Spontaneous Combustion of Coal
}

\author{
Yibo Tang ${ }^{1,2}$ \\ ${ }^{1}$ College of Mining Technology, Taiyuan University of Technology, Taiyuan 030024, China \\ ${ }^{2}$ State Key Laboratory of Coal Resources and Safe Mining, China University of Mining and Technology, Xuzhou, Jiangsu 221116, China \\ Correspondence should be addressed to Yibo Tang; tangyibo11@126.com
}

Received 24 October 2016; Accepted 4 January 2017; Published 31 January 2017

Academic Editor: Vincenza Crupi

Copyright (c) 2017 Yibo Tang. This is an open access article distributed under the Creative Commons Attribution License, which permits unrestricted use, distribution, and reproduction in any medium, provided the original work is properly cited.

\begin{abstract}
Coal spontaneous combustion (CSC) generally induces fire disasters in underground mines, thus causing serious casualties, environmental pollution, and property loss around the world. By using six P-containing additives to process three typical coal samples, this study investigated the variations of the self-ignition characteristics of the coal samples before and after treatment. The analysis was performed by combining thermogravimetric analysis/differential scanning calorimetry (TG/DSC) Fourier transform infrared spectrometer (FTIR) and low temperature oxidation. Experimental results showed that P-containing inhibitors could effectively restrain the heat emitted in the combustion of coal samples and therefore the ignition temperature of the coal samples was delayed at varying degrees. The combustion rate of the coal samples was reduced as well. At the temperatures ranging from $50^{\circ} \mathrm{C}$ to $150^{\circ} \mathrm{C}$, the activation energy of the coal samples after the treatment was found to increase, which indicated that the coal samples were more difficult to be oxidized. After being treated with phosphorus flame retardants (PFRs), the content of several active groups represented by the $\mathrm{C}-\mathrm{O}$ structure in the three coal samples was proved to be obviously changed. This suggested that PFRs could significantly inhibit the content of CO generated by the low temperature oxidation of coal, and the flame-retardant efficiency grew with the increasing temperature. At $200^{\circ} \mathrm{C}$, the maximal inhibition efficiency reached approximately $85 \%$.
\end{abstract}

\section{Introduction}

Coal-mine fire hazards caused by CSC have always been one of the main disasters found in underground mines [1,2]. During 2001-2013, hundreds of serious fire accidents have occurred in China, resulting in over 800 casualties [3]. It is well known that the CSC is one of main reasons responsible for underground mine fire [4]. According to reports, fire disasters aroused by CSC in goafs have occurred in a vast area reaching $56.59 \mathrm{~km}^{2}$ in Shanxi, China, at present. Accordingly, 240 million tons of coal resource is lost, leading to a direct economic loss over 15 billion dollars $[5,6]$. CSC can not only consume valuable coal resource but also generate a large amount of fumes including $\mathrm{CO}, \mathrm{CO}_{2}, \mathrm{SO}_{2}$, and $\mathrm{NO}_{X}[7-$ 9]. As a consequence, it significantly damages and influences the atmospheric environment, vegetation, water, and land resources and also induces various geologic hazards $[9,10]$. To prevent such disasters, people have developed various fire preventing and extinguishing methods [11]. Initially, yellow mud or sand was used to mix with water to prepare grouting [12]. However, this kind of material showed poor performance in some harsh environment. Subsequently, people adopted gel [13], foams [14], and so on to control the low temperature oxidation of coal and prevent fire disasters in goafs. But these materials are expensive and the fire extinguishment efficiency mainly depends on the isolation of coal from air. In terms of chemical flame retardants, the commonly used ones are inorganic salt including $\mathrm{MgCl}_{2}$ and $\mathrm{CaCl}_{2}$ [15]. So far, there are few studies on the effects of P-containing inhibitors. Characterized by halogen-free, low smoke, and low toxicity, PFRs show a high efficiency in few amounts and can be used in various fields. As a result, they have been rapidly developed in recent years. With excellent thermostability, PFRs can generate glassy substances with rich phosphor after dehydration by continuous heating. These glassy substances cover the surface of base materials, thus isolating the air to hinder the continuous combustion of material. Compounds including ammonium polyphosphate 
TABLE 1: Technical parameters of experimental coal samples.

\begin{tabular}{lccccccccccrr}
\hline \multirow{2}{*}{ Name } & \multicolumn{4}{c}{ Proximate analysis } & \multicolumn{4}{c}{ Elemental analysis } & \multicolumn{3}{c}{ Calorific value } \\
& Moisture\% & Ash\% & Volatile\% & Fixed carbon\% & C & H & O & N & S & MJ·kg & Loal rank \\
\hline Zhaotong coal & 8.01 & 20.16 & 48.93 & 30.91 & 52.29 & 3.92 & 30.66 & 1.71 & 0.16 & 18.25 & Lignite \\
Bulianta coal & 4.98 & 6.44 & 32.31 & 63.33 & 81.05 & 4.13 & 13.46 & 0.96 & 0.40 & 32.10 & Subbituminous \\
Xiqu coal & 0.46 & 10.64 & 21.18 & 70.48 & 91.12 & 4.76 & 2.30 & 1.48 & 0.43 & 27.32 & Bituminous \\
\hline
\end{tabular}

TABLE 2: Additives used in the experiment.

\begin{tabular}{lccc}
\hline Name & Chemical formula & Purity & Manufacturer \\
\hline Zinc phosphate & $\mathrm{Zn}_{3}\left(\mathrm{PO}_{4}\right)_{2}$ & $>99 \%$ & Sinopharm Group Co., Ltd. \\
Potassium dihydrogen phosphate & $\mathrm{KH}_{2} \mathrm{PO}_{4}$ & $>99 \%$ & Sinopharm Group Co., Ltd. \\
Sodium hydrogen phosphate & $\mathrm{Na}_{2} \mathrm{HPO}_{4}$ & $>99 \%$ & Sinopharm Group Co., Ltd. \\
Ammonium phosphate & $\left(\mathrm{NH}_{4} \mathrm{PO}_{3}\right) n$ & $>98 \%$ & Taixing Chemical Co., Ltd. \\
Trichloroethyl phosphate & $\mathrm{C}_{6} \mathrm{H}_{12} \mathrm{Cl}_{3} \mathrm{O}_{4} \mathrm{P}$ & $>99 \%$ & Chemical \& Materials Co., Ltd. \\
Diphenyl hydrogen phosphate & $\mathrm{C}_{12} \mathrm{H}_{11} \mathrm{O}_{4} \mathrm{P}$ & $>99 \%$ & Chemical \& Materials Co., Ltd. \\
\hline
\end{tabular}

and phosphate have been widely used in plastic industry and can help to improve the flame-retarding properties of plastics. Wang et al. used microencapsulated red phosphorus and aluminium hypophosphite to jointly inhibit the combustion of polyethylene. Based on the obtained results, they found that using P-containing compounds can reduce the heat emitted in the combustion and enhance the thermostability of polyethylene [16]. Luo et al. synthesized a kind of Pcontaining epoxy resin with high performance through addition reaction, showing good inflaming retarding and mechanical properties [17]. Hence, by using P-containing additives to deal with coal samples, this research studied the influence of P-containing additives on the CSC and explored the chemical inhibition mechanism of PFRs.

\section{Experiments}

In this study, lignite (ZT) collected from Zhaotong in Yunnan, subbituminous coal (BLT) acquired from Bulianta in Inner Mongolia, and bituminous coal (XQ) from Xiqu in Shanxi, China, were served as the coal samples. The specific parameters of these samples are shown in Table 1. To begin with, the fresh coal lump was broken into pieces to select the lumps broken with the length in a range of $0.18-0.25 \mathrm{~mm}$ as the specimens. Then, these specimens were dried in a vacuum drying oven at $50^{\circ} \mathrm{C}$ until their masses maintained unchanged. Next, six kinds of P-containing agents were used as additives (as demonstrated in Table 2) to prepare the solution with a concentration of $5 \%$. Afterwards, $100 \mathrm{~g}$ of coal samples were immersed in $500 \mathrm{ml}$ solution for $24 \mathrm{~h}$, followed by conducting repeated drying. FTIR with the wavenumber varying from 500 to $4,000 \mathrm{~cm}^{-1}$ was used to analyze the coal samples before and after the treatment. Meanwhile, experiments were carried out using TG/DSC to analyze the thermal change of the coal samples in the combustion process in the air at a heating rate of $10^{\circ} \mathrm{C} / \mathrm{min}$. In addition, a temperature programming device (as illustrated in Figure 1) was used to test the generation of $\mathrm{CO}$ in the coal samples before and after the treatment with P-containing agents, as well as to evaluate the inhibition effects. Air was flowed at $20 \mathrm{ml} / \mathrm{min}$ into this device with the temperature ranging from $60^{\circ} \mathrm{C}$ to $200^{\circ} \mathrm{C}$ at a heating rate of $1^{\circ} \mathrm{C} / \mathrm{min}$.

\section{Results and Discussion}

3.1. Infrared Spectroscopic Analysis. As demonstrated in Figure 2 , the absorption peaks of the infrared absorption spectrum for the BLT coal mainly included the out-of-plane stretching vibration induced in case heteroatoms at 508-872 replaced $\mathrm{C}-\mathrm{H}$, the $\mathrm{C}-\mathrm{O}$ vibration between 1077 and 1374, the vibration of aromatic-ring $\mathrm{C}=\mathrm{C}$ band at $1591-1601 \mathrm{~cm}^{-1}$, $2851 \mathrm{~cm}^{-1}$, and the vibration of $-\mathrm{CH}_{2}-$ at $2921 \mathrm{~cm}^{-1}$, as well as the vibration of $\mathrm{OH}$-stretching bands at $3006-3537 \mathrm{~cm}^{-1}$. For the infrared absorption spectrum of the XQ coal, the stretching vibration of heteroatoms between 555 and $914 \mathrm{~cm}^{-1}$, the $\mathrm{C}-\mathrm{O}$ vibration at $1008 \mathrm{~cm}^{-1}$, the vibration of aromatic-ring $\mathrm{C}=\mathrm{C}$ bands at $1437-1607 \mathrm{~cm}^{-1}$, and the vibration of $-\mathrm{CH}_{2}-$ at $2847-2919 \mathrm{~cm}^{-1}$ were primarily contained. In addition, the following absorption peaks were observed in the infrared spectrum for the ZT coal: the absorption peak of heteroatoms at $561-795 \mathrm{~cm}^{-1}$, the stretching vibration of $\mathrm{C}-\mathrm{O}$ at $1003-$ $1342 \mathrm{~cm}^{-1}$, and the vibration of $\mathrm{OH}$-stretching bands at 3025$3697 \mathrm{~cm}^{-1}$. After the treatment using P-containing additives, obvious changes happened to the infrared absorption spectra of these three coal samples. For example, the absorption peak for the $\mathrm{OH}$ structure of the $\mathrm{ZT}$ coal at $3464 \mathrm{~cm}^{-1}$ was enhanced to varying degrees, while the content of the C$\mathrm{O}$ was apparently reduced. As to the BLT coal, the number of $-\mathrm{CH}_{2}$ - and $\mathrm{C}-\mathrm{O}$ structures was obviously lowered. As to the XQ coal, new absorption peaks representing the $\mathrm{OH}$ structure occurred at $3349 \mathrm{~cm}^{-1}$; meanwhile, the absorption peaks for the stretching vibration of $\mathrm{C}-\mathrm{O}$ were weakened at $1054 \mathrm{~cm}^{-1}$. In general, the $\mathrm{C}=\mathrm{C}$ structures in these three coal samples exhibited moderate variation, while the content of the $\mathrm{C}-\mathrm{O}$ structure reduced. The $\mathrm{C}-\mathrm{O}$ structure is the critical structure influencing the low temperature oxidation of coal [18], which revealed that phosphorous flame retardants can 


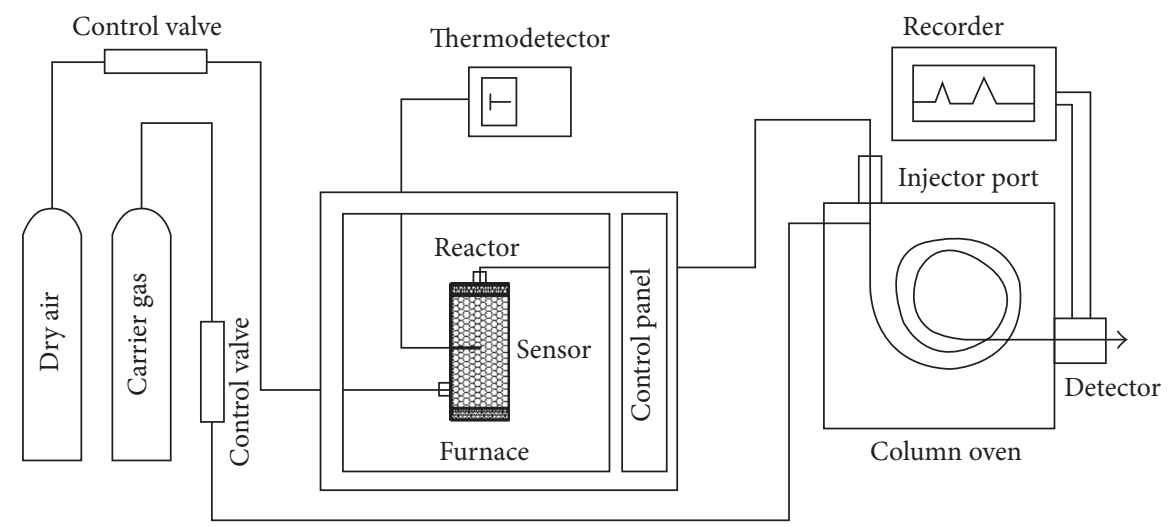

FIgURE 1: The experimental setup.

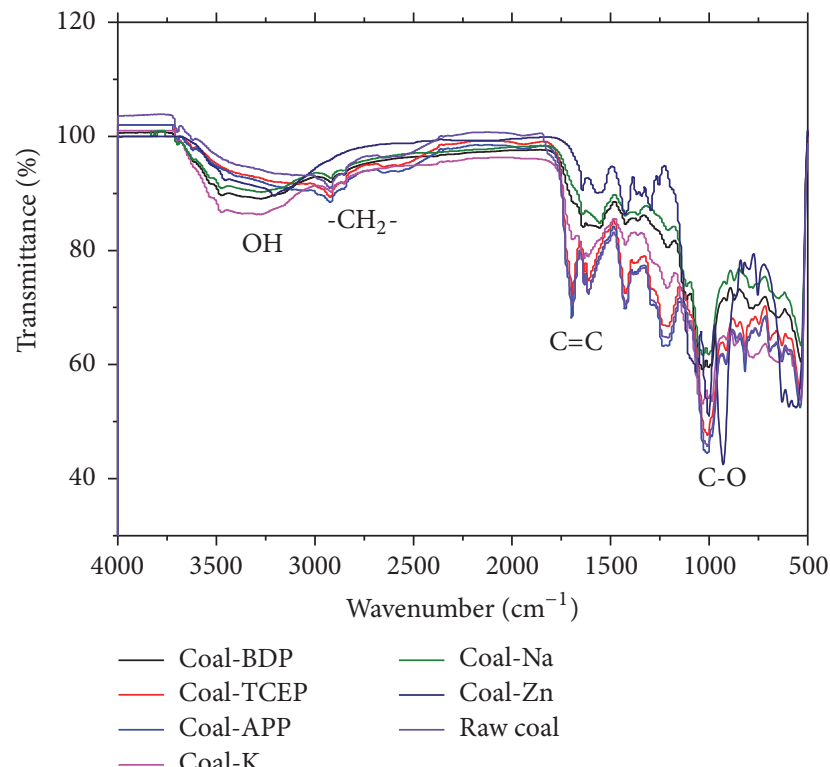

(a) ZT coal

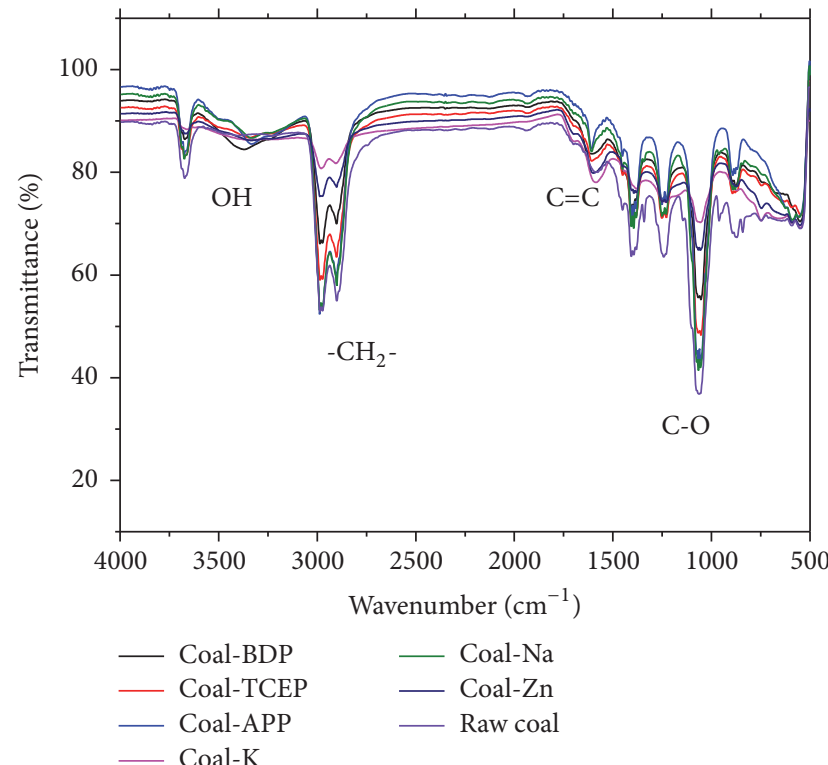

(b) BLT coal

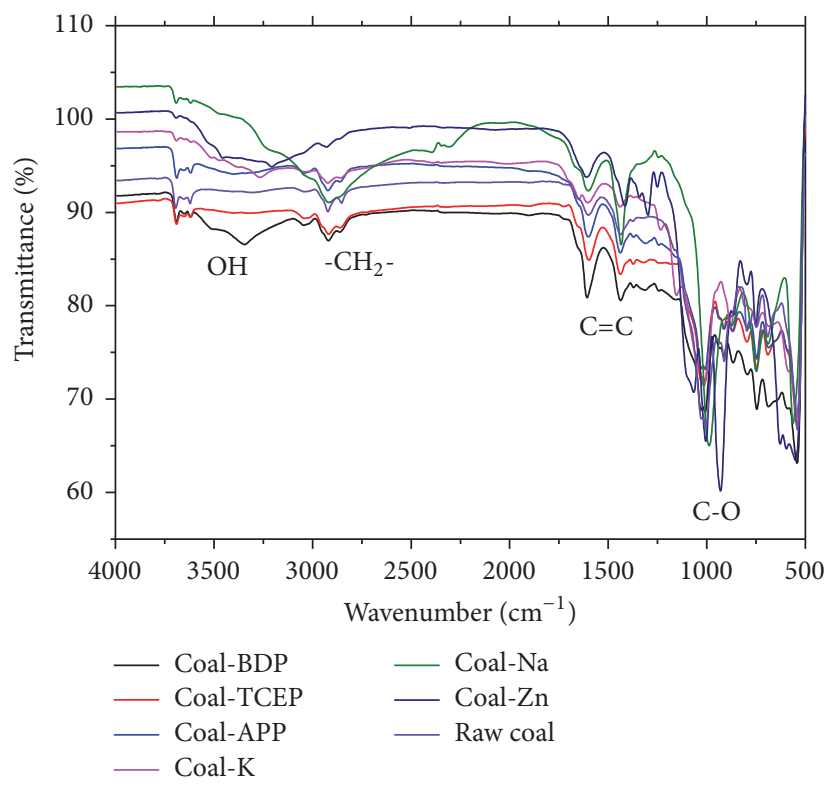

(c) XQ coal

FIGURE 2: The FTIR of coal samples before and after treatment. 


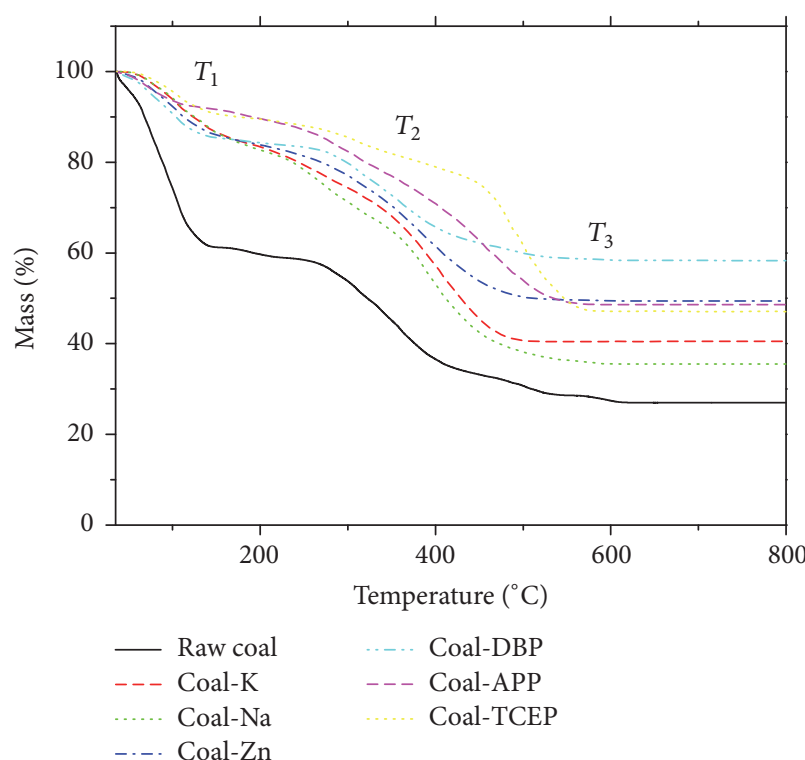

(a) ZT coal

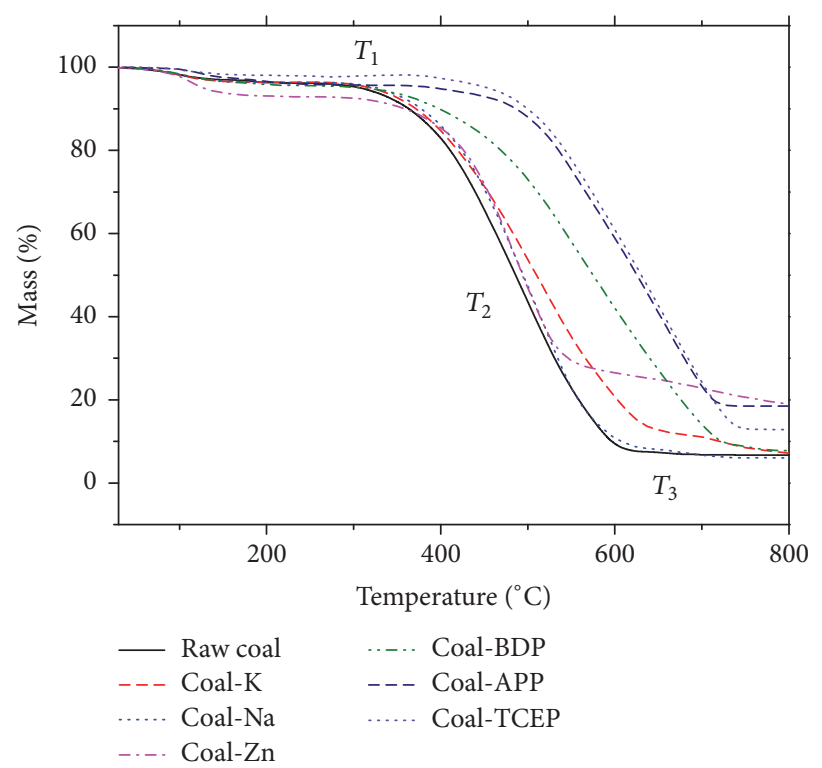

(b) BLT coal

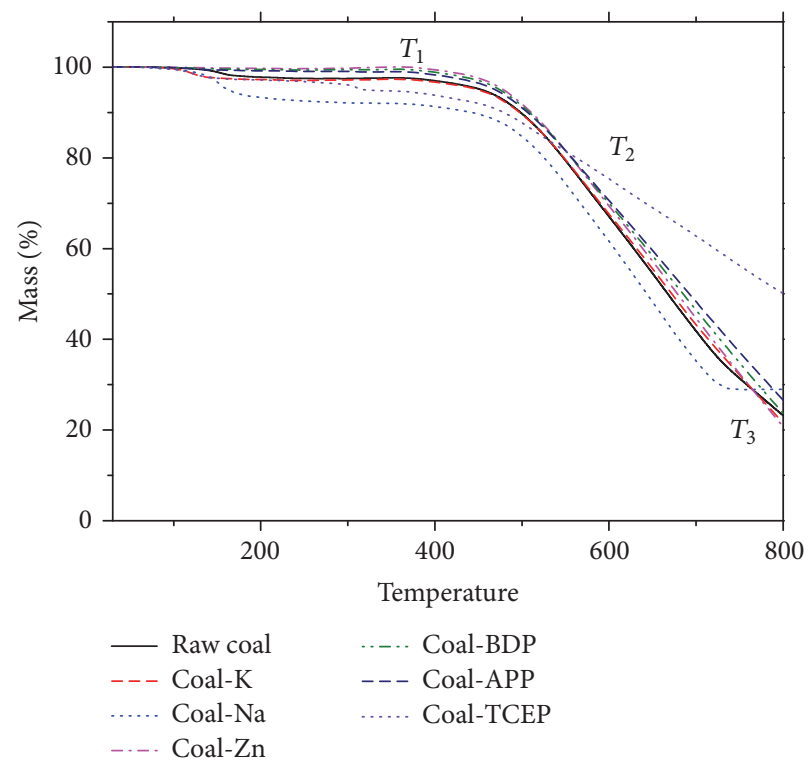

(c) XQ coal

FIgURE 3: The TG curves of coal samples before and after treatment.

weaken the active structures including oxygen-containing functional groups in coal, thus affecting the low temperature oxidation of coal.

3.2. Thermal Analysis. Based on the thermal analysis, it was found that, after the treatment using P-containing additives, the thermogravimetric curves of the coal samples varied in different degrees. According to Figure 3, the combustion of coal can be divided into three stages: precombustion, combustion, and stabilization. Before $200^{\circ} \mathrm{C}$, all three coal samples show similar trend in TG and DSC curves. The Pcontaining inhibitors play a significant role on the controlling of low temperature oxidation. And this phenomenon remains with the temperature increasing. For the ZT brown coal, raw coal was gradually oxidized with the increasing temperature before $200^{\circ} \mathrm{C}$, while it was rapidly combusted and decomposed when the temperature varied from $250^{\circ} \mathrm{C}$ to $300^{\circ} \mathrm{C}$. After the temperature reached $600^{\circ} \mathrm{C}$, the combustion basically stopped and the mass of the coal maintained stable. After the addition of the P-containing inhibitors, the coal was slowly burned and it can be found that both the critical temperature $T_{1}$ and combustion temperature $T_{2}$ of the coal were obviously postponed and the mass loss rate of the coal was also slowed down. Similarly, as shown in Figure 4, the differential scanning calorimetry (DSC) curve of the ZT coal indicated that the heat emitted by the treated coal sample 


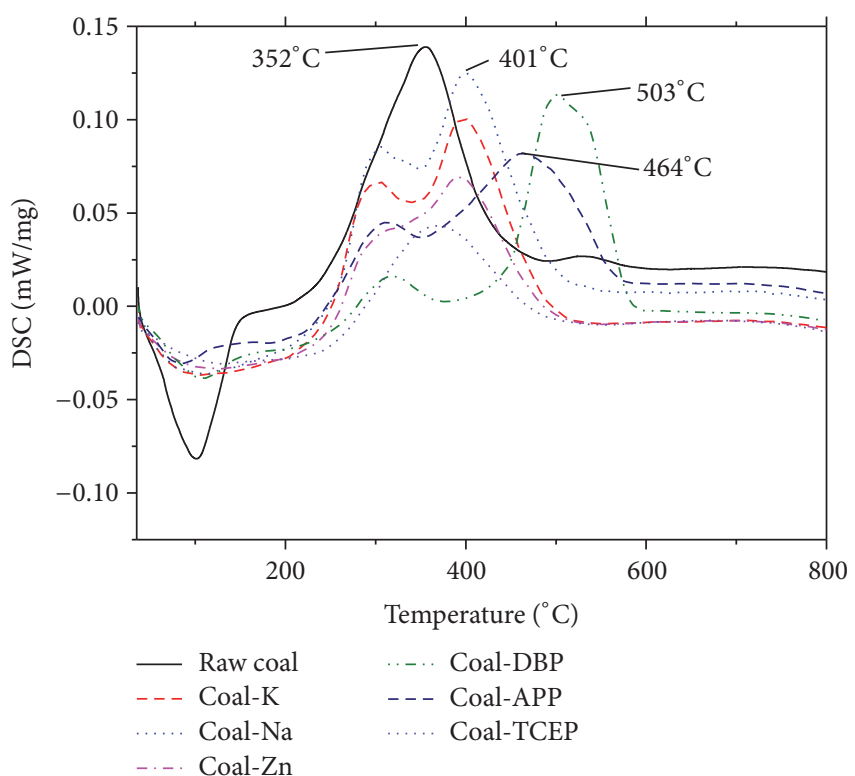

(a) ZT coal

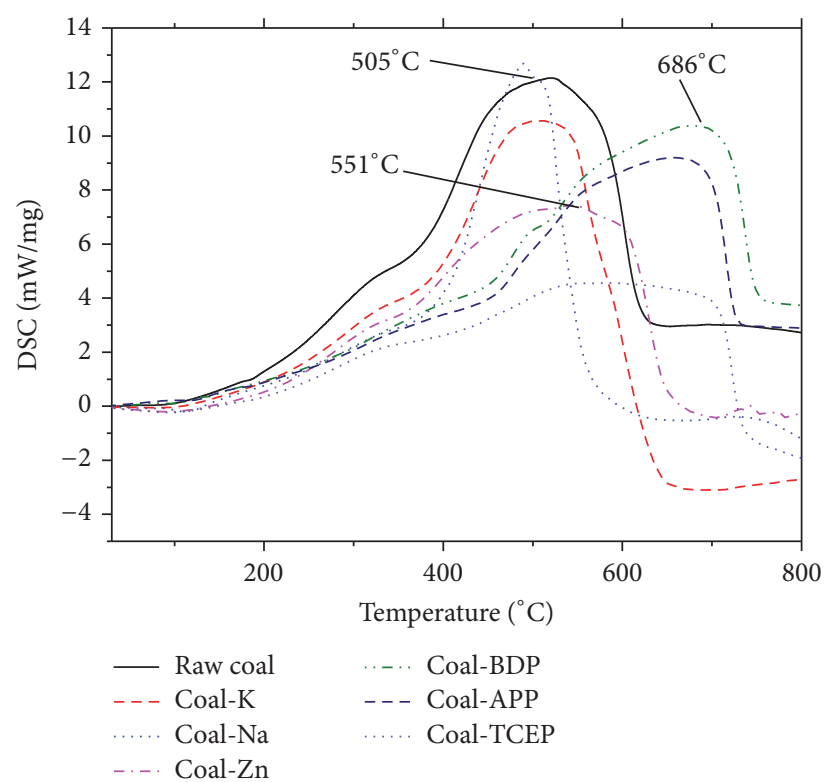

(b) BLT coal

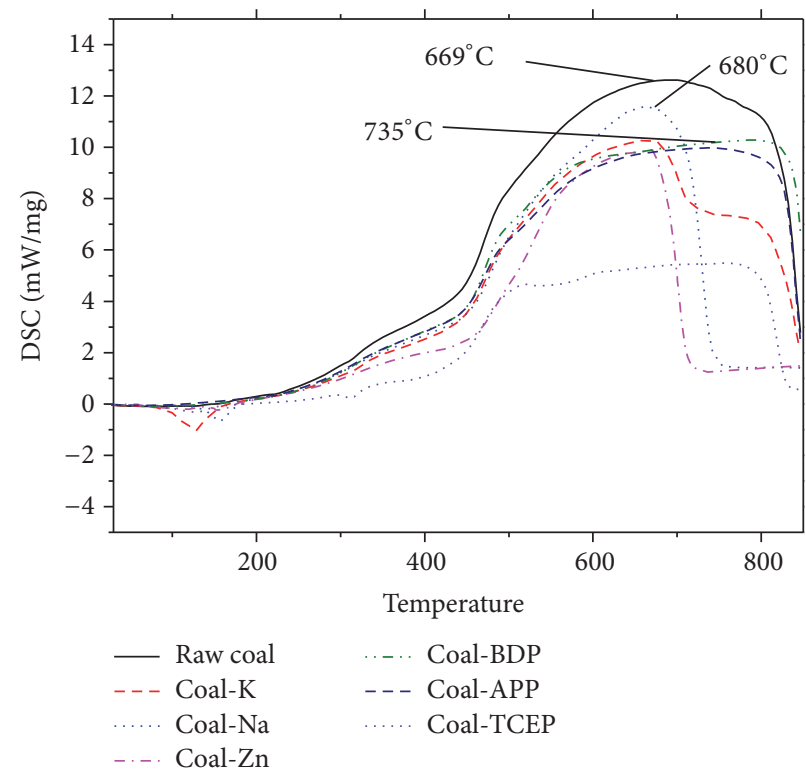

(c) XQ coal

Figure 4: The DSC curves of coal samples before and after treatment.

was also changed: not only the heat released reduced, but also the temperature at which the greatest exothermic peak delayed occurred. In contrast, the BLT and XQ coal also showed similar rules, that is, the heat released by the coal after the treatment was significantly lowered. For example, the exothermic peak of ZT raw coal in DSC curve is $352^{\circ} \mathrm{C}$. After the treatment by BDP, this temperature postpones to $503^{\circ} \mathrm{C}$. The masses of these two kinds of coal samples were slightly changed owing to the addition of P-containing flame retardants before $200^{\circ} \mathrm{C}$. Between 200 to $400^{\circ} \mathrm{C}$, this tendency has been further strengthened. At $300^{\circ} \mathrm{C}$, the heat flux of XQ raw coal is $1.486 \mathrm{~mW} / \mathrm{mg}$, while the date of coal treated by TCEP is only $0.263 \mathrm{~mW} / \mathrm{mg}$. However, after the temperature reaches $400^{\circ} \mathrm{C}$, the coal samples were burned and therefore remarkable difference was shown to the mass loss rates of the coal samples before and after the treatment.

This suggested that PFRs can be used to effectively control the combustion of coal.

The oxygenolysis of coal was a typical gas-solid reaction. Assuming that reaction order of coal was 1 , according to chemical reaction kinetics, the activation energy of the coal was calculated by adopting the Coats-Redfern integral formula [19]:

$$
\ln \left[\frac{g(a)}{T^{2}}\right]=\ln \left[\frac{A R}{\beta E_{a}}\left(1-\frac{2 R T}{E_{a}}\right)\right]-\frac{E}{R T},
$$




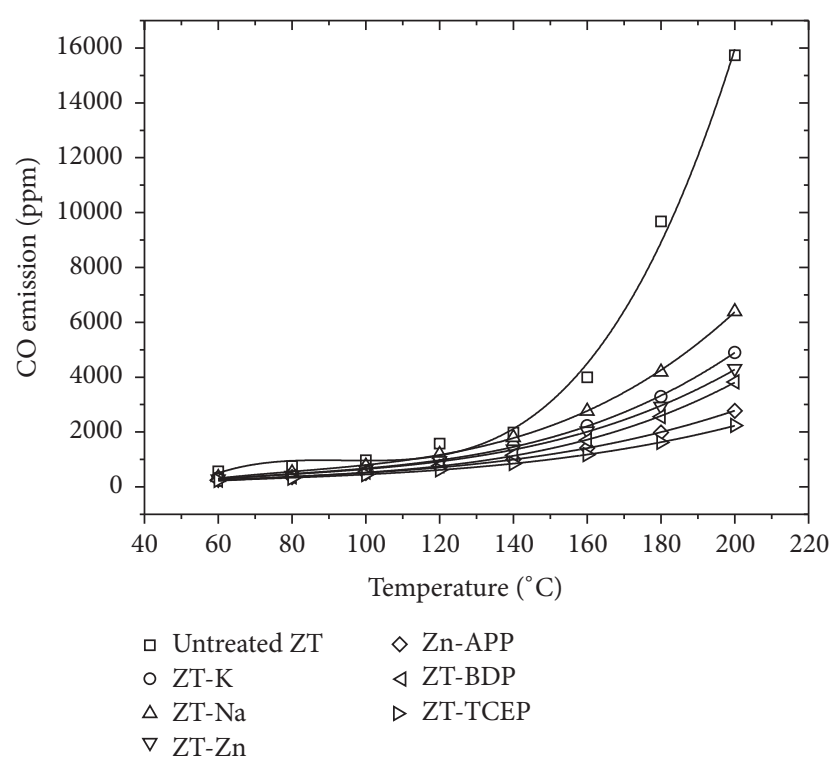

(a) ZT coal

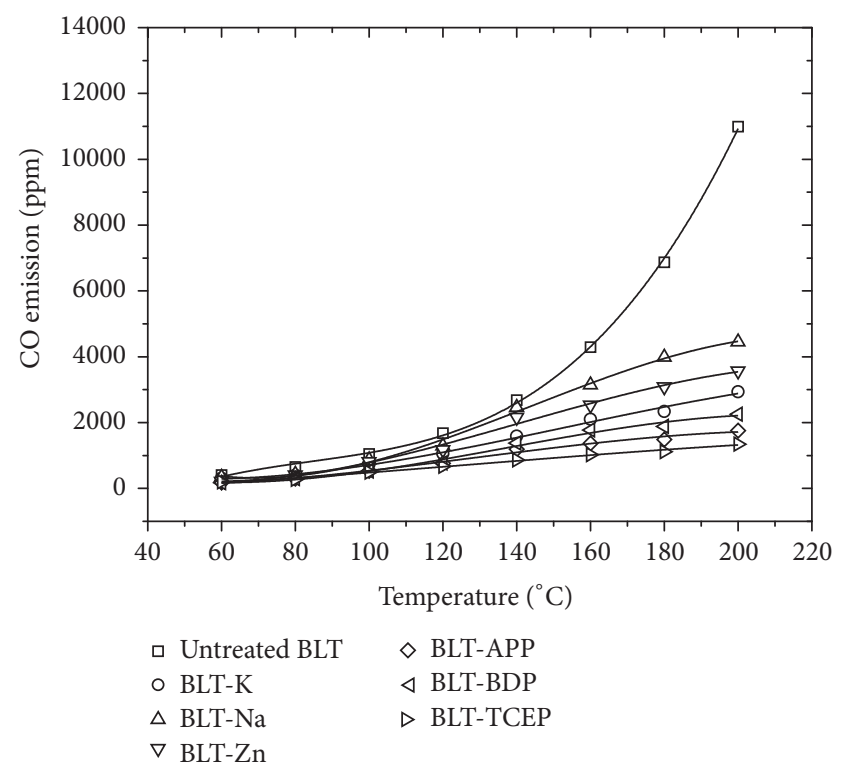

(b) BLT coal

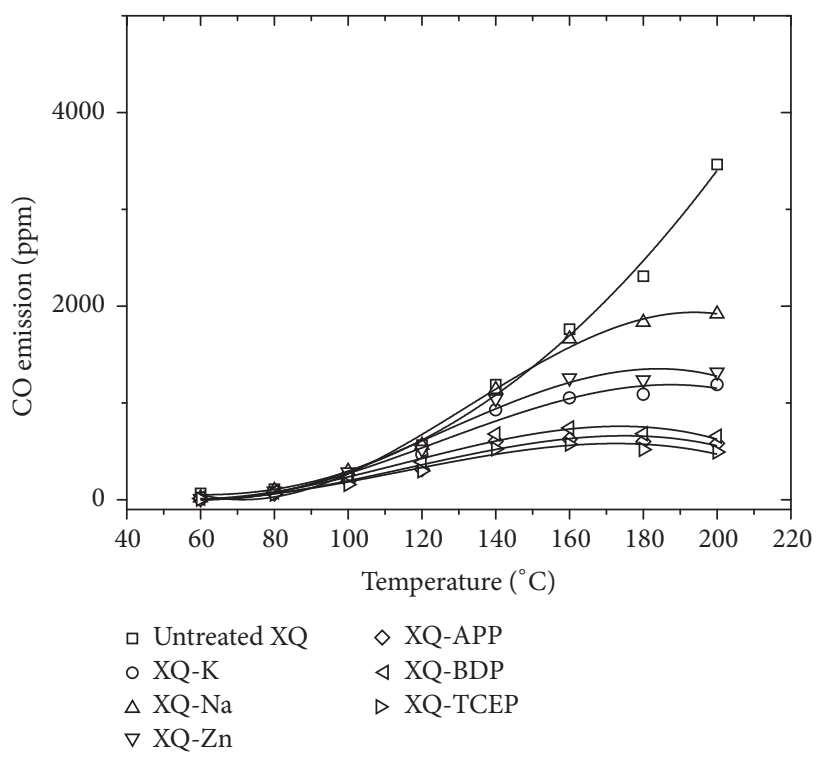

(c) XQ coal

FIgURE 5: The CO emission of coal samples before and after treatment.

where $a$ represented transformation percentage of coal in oxygenolysis process, $\beta$ represented heating rate, and $g(a)$ was integral formula of function model, which reflected mechanism of oxidation reaction of coal. $g(a)=-\ln (1-$ a). Meanwhile, $t$ was reaction time, $T$ was reaction temperature, $A$ was preexponential factor, $E_{a}$ was activation energy induced by oxygenolysis of coal, and $R$ represented gas constant. Based on mechanism of the chemical reaction kinetics, the construction on $l / T$ was performed by utilizing $\ln \left(-\ln (1-a) / T^{2}\right)$. Besides, according to the obtained slope, activation energy $E_{a}$ of the reaction was expected to be calculated. According to Table 3, the activation energy of the coal samples after the treatment was improved to different degrees when the temperature varied from $50^{\circ} \mathrm{C}$ to $150^{\circ} \mathrm{C}$ in comparison with those before the treatment. After the treatment using inorganic phosphorus agents, the coal dealt with zinc phosphate showed a significant change to the activation energy. In contrast, the optimal effects were found to the coal treated with the organic phosphorus agent tris(2chloroethyl) phosphate (TCEP). The improvement of the activation energy indicated that the higher the energy needed for the low temperature oxidation of coal is, the more difficult the reaction happens.

3.3. Oxidation Products. As seen in Figure 5, as an index gas of CSC, the CO released in the oxidation of coal samples presented increased concentrations with the temperature. However, after the treatment using PFRs, the concentrations 
TABLE 3: Activation energy of the coal samples before and after treatment.

\begin{tabular}{|c|c|c|c|c|c|c|c|}
\hline \multirow{2}{*}{ Coal samples } & \multicolumn{7}{|c|}{ Activation energy $/\left(\mathrm{kJ} \cdot \mathrm{mol}^{-1}\right)$} \\
\hline & Raw coal & Coal-K & Coal-Na & Coal-Zn & Coal-BDP & Coal-APP & Coal-TCEP \\
\hline ZT & 74.6 & 76.4 & 77.3 & 75.7 & 98.1 & 81.4 & 114.6 \\
\hline BLT & 76.1 & 83.2 & 78.3 & 80.5 & 82.1 & 90.6 & 115.2 \\
\hline XQ & 119.8 & 130.1 & 124.7 & 126.5 & 131.9 & 142.6 & 178.9 \\
\hline
\end{tabular}

of CO caused by the combustion of coal samples apparently varied. For the XQ coking coal before the treatment, $259 \mathrm{ppm}$ of $\mathrm{CO}$ was generated in the oxidation process at $100^{\circ} \mathrm{C}$. However, after the treatment, the concentration of CO produced reduced to $156 \mathrm{ppm}$ at minimum. With the increasing temperature, the coal samples treated with TCEP generated $493 \mathrm{ppm}$ of $\mathrm{CO}$ at $200^{\circ} \mathrm{C}$. Similar rules were also shown to the BLT and ZT coal. At $200^{\circ} \mathrm{C}$, the concentrations of $\mathrm{CO}$ released by the BLT coal before and after the treatment were $10,994 \mathrm{ppm}$ and $1345 \mathrm{ppm}$, separately, while those emitted by the ZT coal were $15,732 \mathrm{ppm}$ at maximum and $2240 \mathrm{ppm}$ at minimum. The inhibiting efficiency is expressed as shown in the following formula:

$$
E=\frac{\mathrm{Cr}-\mathrm{Ct}}{\mathrm{Cr}} \times 100 \%,
$$

where $E$ is the inhibiting rate of the inhibitor to the coal sample; $\mathrm{Cr}$ denotes the amount of $\mathrm{CO}$ released from the raw coal in the experiment with the unit of $10^{-6}$; Ct shows the amount of $\mathrm{CO}$ released from the coal treated with the inhibitor under the same condition with the unit of $10^{-6}$.

According to the results calculated using formula (2), the maximal inhibiting rates of the phosphorous flame retardants to the ZT, BLT, and XQ coal were shown to be $53.5 \%, 52.9 \%$, and $39.6 \%$ at $100^{\circ} \mathrm{C}$, respectively. While these values changed to $85.7 \%, 87.1 \%$, and $86.4 \%$ at $200^{\circ} \mathrm{C}$, separately. This revealed that, compared with the combustion at a temperature lower than $100^{\circ} \mathrm{C}$, the phosphorous flame retardants show more obvious inhibition effects on the CSC at a high temperature. Besides, comparing with the $\mathrm{CO}$ production, the $\mathrm{CO}_{2}$ and $\mathrm{C}_{2} \mathrm{H}_{4}$ emission show the similar performance after the treatment of PFRs (Figures 6 and 7). For example, the ZT coal

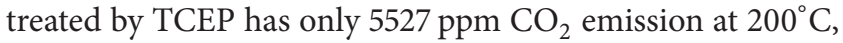
while the raw coal peaks at $39343 \mathrm{ppm}$. At $200^{\circ} \mathrm{C}$, the $\mathrm{C}_{2} \mathrm{H}_{4}$ yield of BLT coal climbs to $432 \mathrm{ppm}$, but the coal treated by ammonium phosphate (APP) only reaches $141 \mathrm{ppm}$.

3.4. Flame-Retardant Mechanism. With the application of PFRs, phosphorus compounds were decomposed in the combustion process of polymers with P-containing flame retardants owing to the effect of heat, accompanying with the following changes [20]:

$$
\text { P-containing compounds } \stackrel{\text { heating }}{\longrightarrow}
$$

$$
\begin{gathered}
\text { phosphoric acid } \stackrel{\text { heating }}{\longrightarrow} \text { metaphosphoric acid } \stackrel{\text { heating }}{\longrightarrow} \\
\text { polymetaphosphate }
\end{gathered}
$$

Polymetaphosphate, as a nonvolatile stable compound, covers on the surface of the polymer, thus forming a charring layer. Since no flaming evaporative combustion or decomposition combustion would happen to simple substance carbon, polymetaphosphate can inhibit the combustion. In addition, since phosphoric acid and polymetaphosphate show strong dehydration properties, carbonized films were formed on the surface of the polymer, thus inhibiting the combustion. This is the flame-retardant mechanism of PFRs in the condensed phase of polymers. PFRs are also a kind of radical scavengers. The mass-spectrometric technique revealed that $\mathrm{PO}$ was generated in any P-containing compounds in the combustion of polymers. It can combine with the hydrogen atoms in the flaming area, thus restraining the flaming [21]. The specific action is expressed as

$$
\begin{gathered}
\mathrm{PO} *+\mathrm{H} * \longrightarrow \mathrm{HPO} * \\
\mathrm{HPO} *+\mathrm{H} * \longrightarrow \mathrm{H}_{2}+\mathrm{PO} *
\end{gathered}
$$

The phosphorus could inhibit the self-ignition of coal efficiently. Superabundant phosphorus in coal also work against the clean and efficient utilization of coal. When the coal was adopted as boiler fuel, P-containing compounds in coal will decompose at high temperature and then form sediments which are difficult to clear on the heating surface of boiler. Moreover, during the iron-making and steel-making process, the existence of phosphorus element will influence the quality of iron and steel. As the results, the content of phosphorus in coal is strictly limited around the world. Considering safety factors, phosphorus flame retardants could be widely applied in the abandoned area of colliery, such as gob, goaf, and coal waste heap. However, we still need comprehensively assessment before being utilized in storage and transportation of coal.

\section{Conclusions}

It is essential to use effective flame retardants for the prevention of CSC so as to further guarantee the mine safety. Although PFRs have played a significant role in the industrial production of polymers, more exploration is still needed in its role in the inhibition of CSC. Laboratorial research was attempted to explore the inhibition mechanism of PFRs on the organic functional groups in coal molecules. The experimental results revealed that phosphorus could effectually inhibit CSC at a high temperature interval. Although certain effects could also be emerged at a low temperature range, they were less obvious compared with that at a high temperature with a maximal inhibiting rate above $80 \%$. 


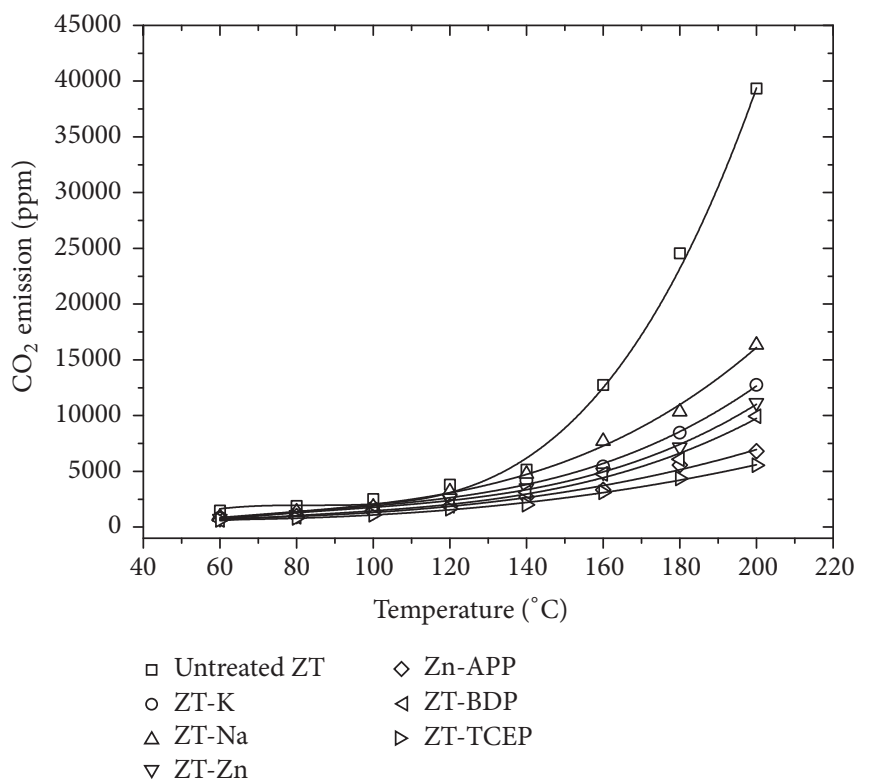

(a) ZT coal

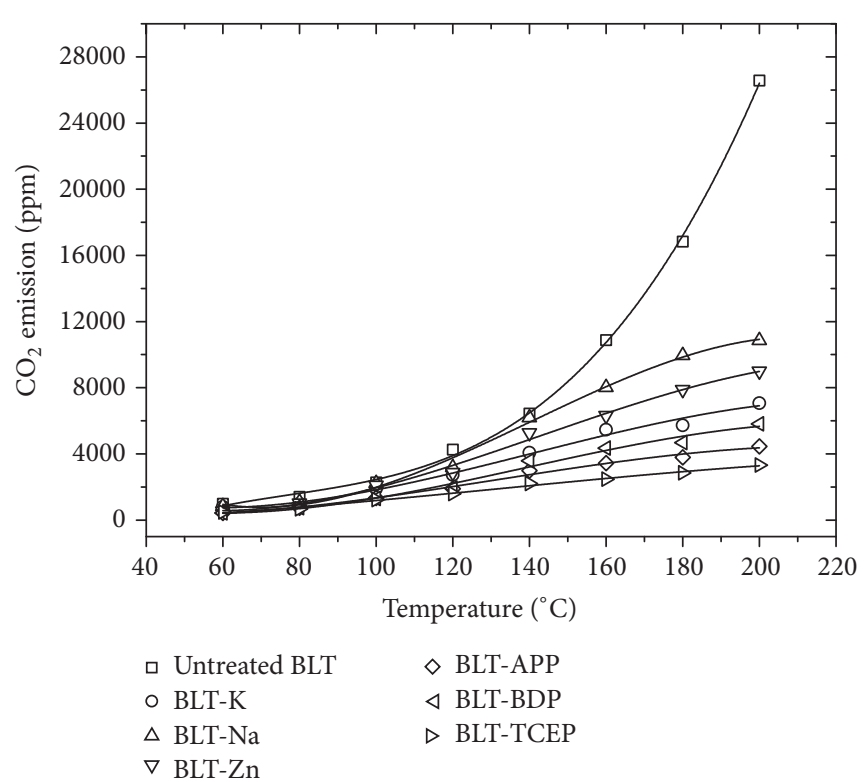

(b) BLT coal

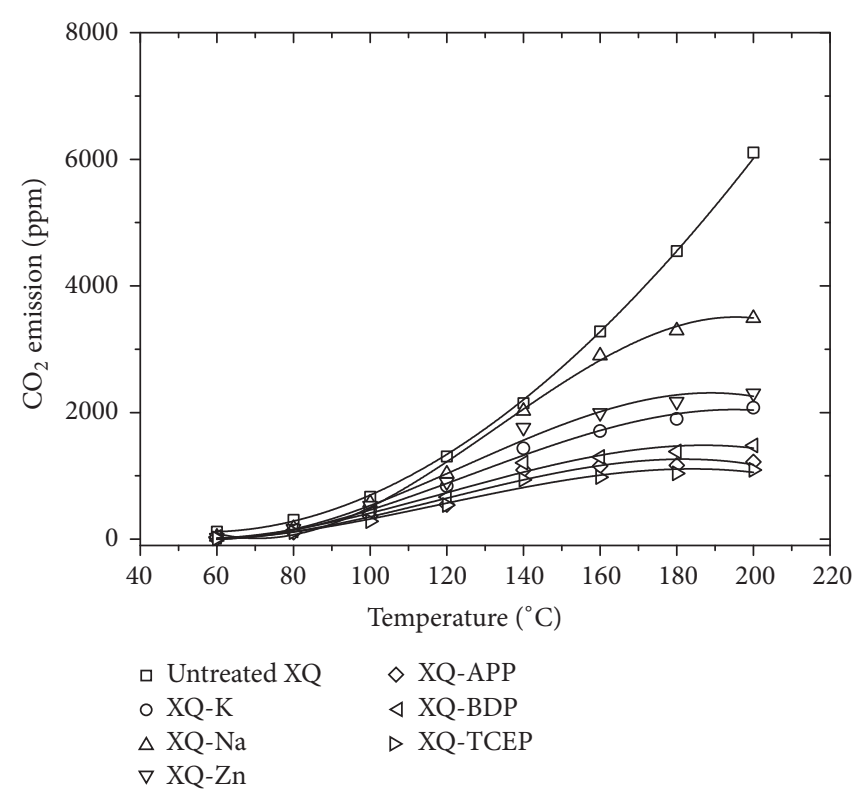

(c) XQ coal

FIGURE 6: The $\mathrm{CO}_{2}$ emission of coal samples before and after treatment.

The results obtained using the FTIR indicated that, for the coal samples with different coal ranks, the C-O structures in the coal after the treatment were obviously weakened. Similar results were also obtained in the thermal analysis and temperature programming experiment: using P-containing compounds can reduce the heat released in the combustion of coal and increase the difficulty in the reaction between coal and oxygen. This research provides a favorable reference to the application of P-containing inhibitors.

\section{Competing Interests}

The author declares that they have no competing interests.

\section{Acknowledgments}

This study is funded by the Project of China National Natural Science Foundation (no. 51604185), Open Projects of State Key Laboratory of Coal Resources and Safe Mining, CUMT 


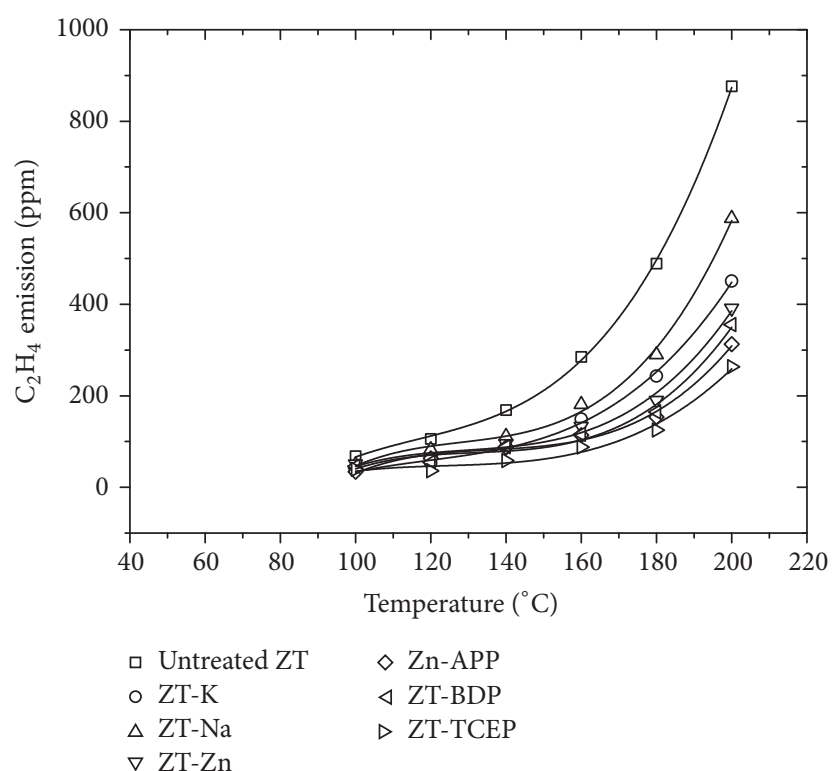

(a) ZT coal

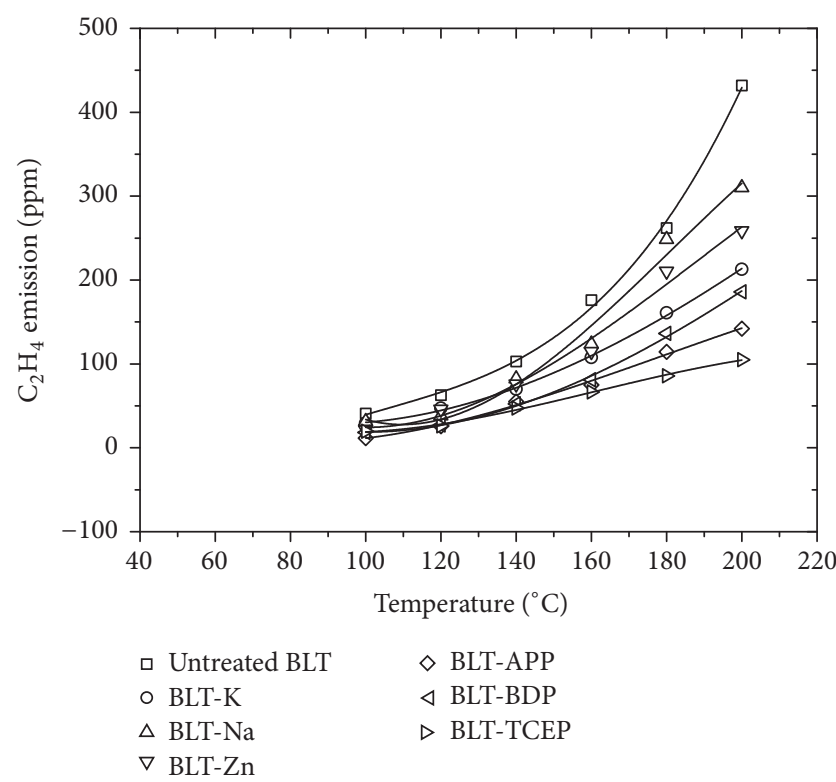

(b) BLT coal

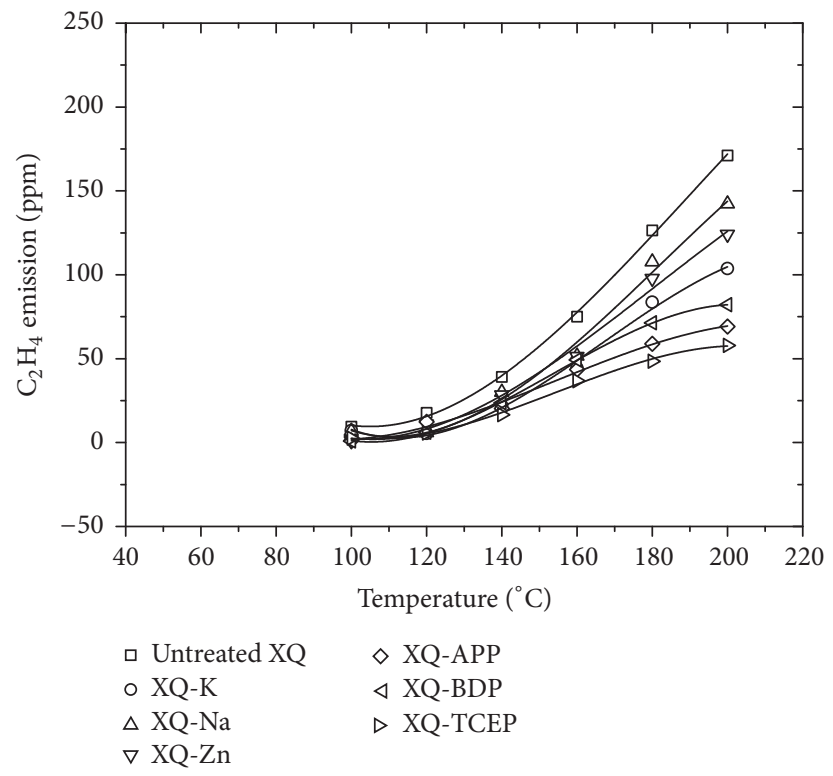

(c) XQ coal

Figure 7: The $\mathrm{C}_{2} \mathrm{H}_{4}$ emission of coal samples before and after treatment.

(SKLCRSM15KF07), and the Research Project Supported by Shanxi Scholarship Council of China (2015-037).

\section{References}

[1] J. Zhang, W. Choi, T. Ito, K. Takahashi, and M. Fujita, "Modelling and parametric investigations on spontaneous heating in coal pile," Fuel, vol. 176, pp. 181-189, 2016.

[2] C. Avila, T. Wu, and E. Lester, "Petrographic characterization of coals as a tool to detect spontaneous combustion potential," Fuel, vol. 125, pp. 173-182, 2014.

[3] Q. Deng, Y. Wang, and M. Liu, "Statistic analysis and enlightenment on coal mine accident of China from 2001 2013 periods," Coal Technology, vol. 33, no. 9, pp. 73-75, 2014.
[4] Y. Tang and S. Xue, "Laboratory study on the spontaneous combustion propensity of lignite undergone heating treatment at low temperature in inert and low-oxygen environments," Energy \& Fuels, vol. 29, no. 8, pp. 4683-4689, 2015.

[5] R. Song, "Geological exploration and treatment method of spontaneous combustion of coal seam," in Coal Geology Bureau of Shanxi Province, Taiyuan, pp. 65-68, 2012.

[6] J. Liu, E. Wang, D. Song, S. Wang, and Y. Niu, "Effect of rock strength on failure mode and mechanical behavior of composite samples," Arabian Journal of Geosciences, vol. 8, no. 7, pp. 45274539, 2015.

[7] Y. Tang, "Sources of underground CO: crushing and ambient temperature oxidation of coal," Journal of Loss Prevention in the Process Industries, vol. 38, pp. 50-57, 2015. 
[8] J. C. Hower, J. M. K. O’Keefe, K. R. Henke et al., "Gaseous emissions and sublimates from the Truman Shepherd coal fire, Floyd County, Kentucky: a re-investigation following attempted mitigation of the fire," International Journal of Coal Geology, vol. 116-117, pp. 63-74, 2013.

[9] G. B. Stracher and T. P. Taylor, "Coal fires burning out of control around the world: thermodynamic recipe for environmental catastrophe," International Journal of Coal Geology, vol. 59, no. 1-2, pp. 7-17, 2004.

[10] C. L. Dias, M. L. S. Oliveira, J. C. Hower, S. R. Taffarel, R. M. Kautzmann, and L. F. O. Silva, "Nanominerals and ultrafine particles from coal fires from Santa Catarina, South Brazil," International Journal of Coal Geology, vol. 122, pp. 50-60, 2014.

[11] B. Taraba and Z. Pavelek, "Investigation of the spontaneous combustion susceptibility of coal using the pulse flow calorimetric method: 25 years of experience," Fuel, vol. 125, pp. 101105, 2014.

[12] Y. Yang, Z. Li, S. Hou, F. Gu, S. Gao, and Y. Tang, "The shortest period of coal spontaneous combustion on the basis of oxidative heat release intensity," International Journal of Mining Science and Technology, vol. 24, no. 1, pp. 99-103, 2014.

[13] Y. Lu and B. Qin, "Mechanical properties of inorganic solidified foam for mining rock fracture filling," Materials Express, vol. 5, no. 4, pp. 291-299, 2015.

[14] L. Zhang, B. Qin, B. Shi, Q. Wu, and J. Wang, "The fire extinguishing performances of foamed gel in coal mine," Natural Hazards, vol. 81, no. 3, pp. 1957-1969, 2016.

[15] Y.-B. Tang, Z.-H. Li, Y. I. Yang, D.-J. Ma, and H.-J. Ji, "Effect of inorganic chloride on spontaneous combustion of coal," Journal of the Southern African Institute of Mining and Metallurgy, vol. 115, no. 2, pp. 87-92, 2015.

[16] D. K. Wang, H. He, and P. Yu, "Flame-retardant and thermal degradation mechanism of low-density polyethylene modified with aluminum hypophosphite and microencapsulated red phosphorus," Journal of Applied Polymer Science, vol. 133, no. 13, Article ID 43225, 2016.

[17] Q. Luo, Y. Yuan, C. Dong, S. Liu, and J. Zhao, "High performance fire-retarded epoxy imparted by a novel phenophosphazine-containing antiflaming compound at ultra-low loading," Materials Letters, vol. 169, pp. 103-106, 2016.

[18] Y. Tang, "Analysis of coals with different spontaneous combustion characteristics using infrared spectrometry," Journal of Applied Spectroscopy, vol. 82, no. 2, pp. 316-321, 2015.

[19] Y. Tang, "A laboratorial study of spontaneous combustion characteristics of the oil shale in Fushun, China," Combustion Science and Technology, vol. 188, no. 6, pp. 997-1010, 2016.

[20] E. D. Weil and S. V. Levchik, "13-Overview of modes of action and interaction of flame retardants," in Flame Retardants, pp. 323-338, Hanser, 2nd edition, 2016.

[21] Y. Tang, "Inhibition of low-temperature oxidation of bituminous coal using a novel phase-transition aerosol," Energy \& Fuels, vol. 30, no. 11, pp. 9303-9309, 2016. 

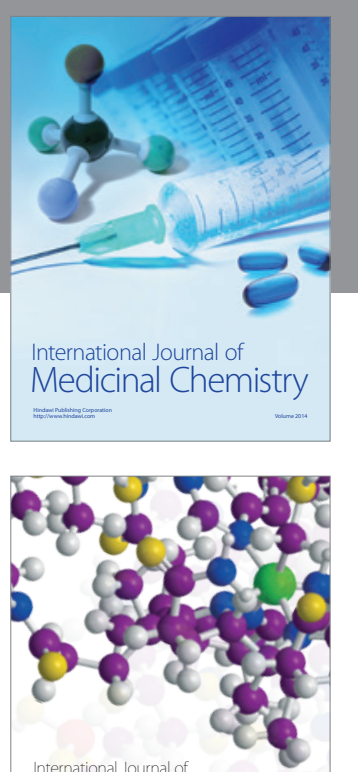

Carbohydrate Chemistry

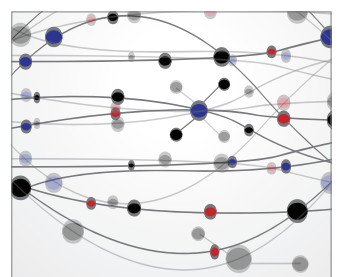

The Scientific World Journal
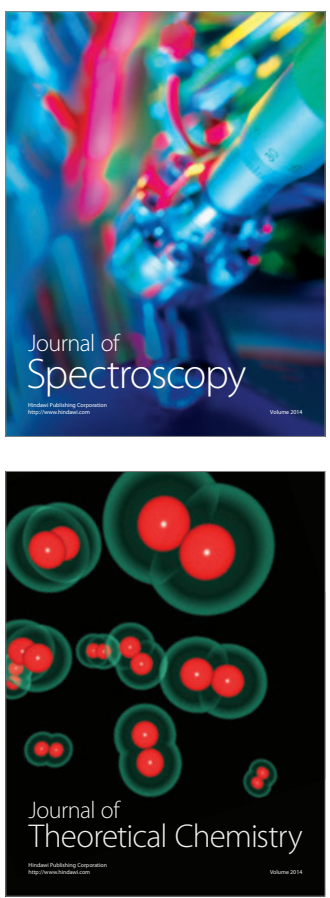
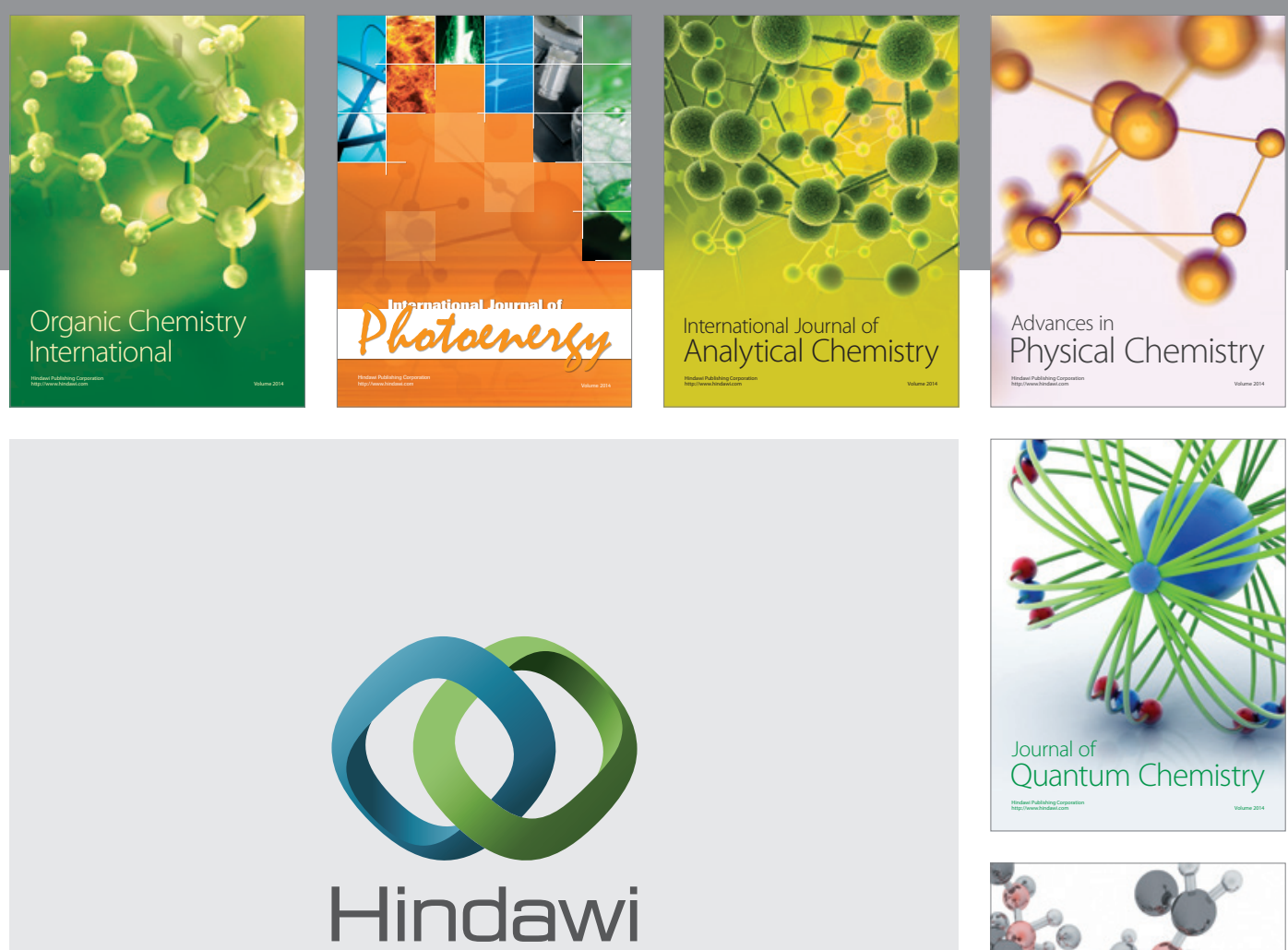

Submit your manuscripts at

https://www.hindawi.com

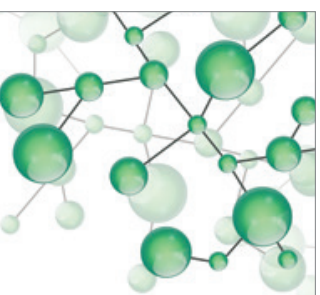

International Journal of

Inorganic Chemistry
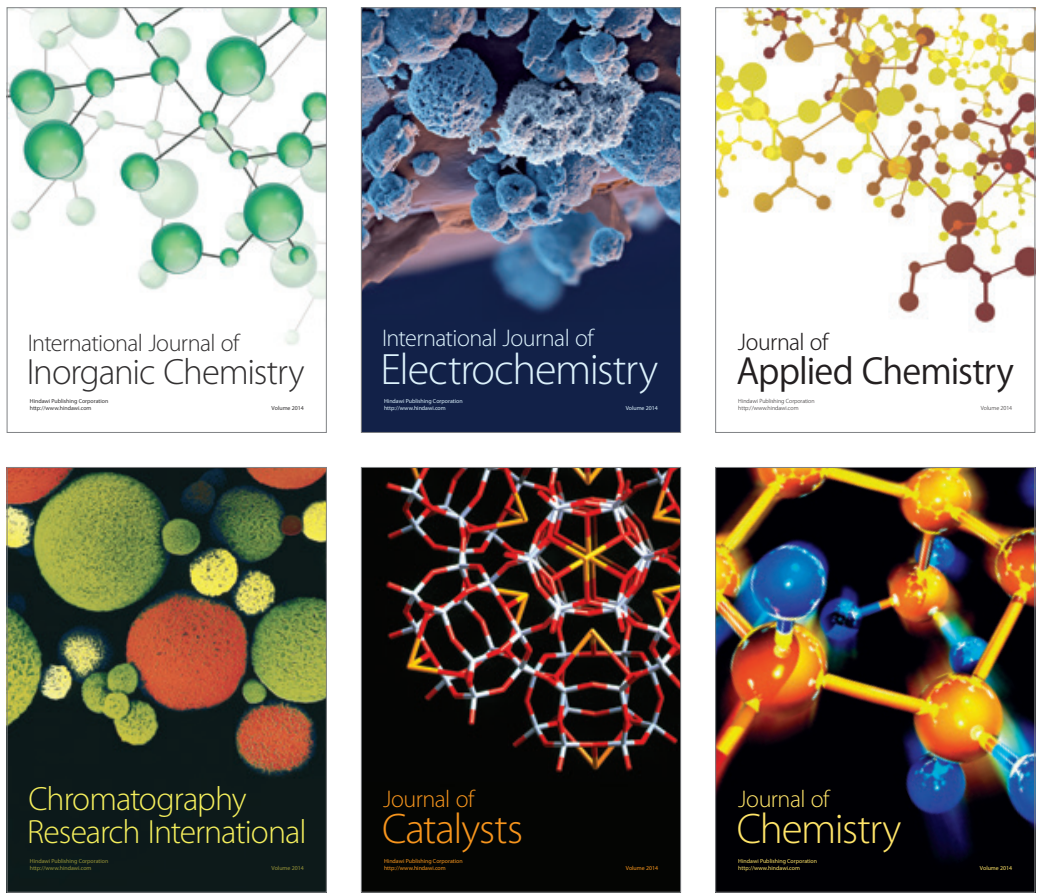

Journal of

Applied Chemistry
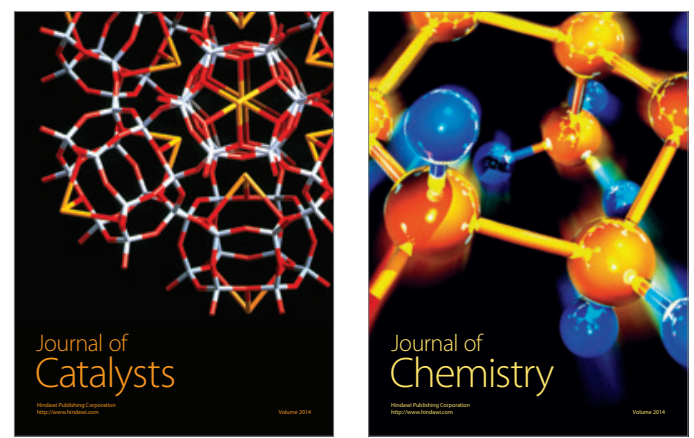
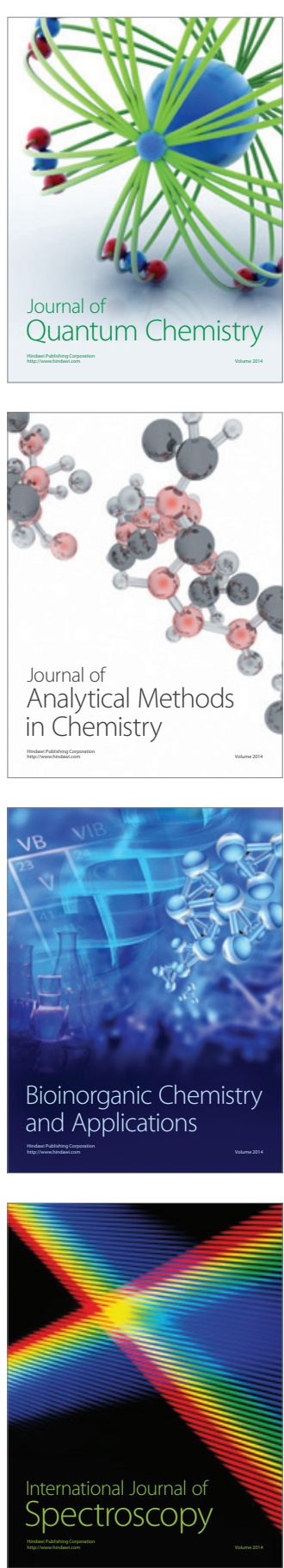